\title{
Theoretical Constructs of Dissent Leadership: Moving from Theory to Practice
}

\author{
Kent L. Willis ${ }^{1}$, Christina Tuell ${ }^{2}$ \\ ${ }^{1}$ The University of Texas Health Science Center at Tyler, Tyler, USA \\ ${ }^{2}$ The University of Houston, Houston, USA \\ Email: kent.willis@uthct.edu,ctuell@cougarnet.uh.edu
}

How to cite this paper: Willis, K. L., \& Tuell, C. (2020). Theoretical Constructs of Dissent Leadership: Moving from Theory to Practice. Open Journal of Leadership, 9, 214-222.

https://doi.org/10.4236/ojl.2020.94013

Received: November 3, 2020

Accepted: December 21, 2020

Published: December 24, 2020

Copyright (c) 2020 by author(s) and Scientific Research Publishing Inc. This work is licensed under the Creative Commons Attribution International License (CC BY 4.0).

http://creativecommons.org/licenses/by/4.0/

(c) (i) Open Access

\begin{abstract}
This paper introduces a construct for moving from theory to practice by underpinning the dissent leadership approach with the theory of distributed leadership. Navigating the decision-making process during uncertain times, such as the global coronavirus (COVID-19) pandemic, presented critical challenges for stakeholders across organizations. A single explanatory conceptual framework derived from the theory of distributed leadership is presented. This framework specifies four competencies that ensure diversity in the workforce increases: 1) leveraging personal and social identities, 2) utilizing a global and diverse mindset, 3 ) leveraging community and organizational contexts, and 4) promoting a diversity-supportive and inclusive climate (Chin et al., 2016; Cammarota, 2011). Furthermore, this paper reconceptualizes dissent leadership as a mechanism for equitable and inclusive decision-making. Leveraging diverse points of view may strengthen organizational responses to large scale operational disruption such as the 2019 global coronavirus (COVID-19) pandemic.
\end{abstract}

\section{Keywords}

Dissent Leadership, Theory of Distributed Leadership, Discourse Analysis, Stance-Taking Behaviors

\section{Background of the Problem}

Organizations and workplaces develop a culture of assumed leadership and unwritten rules that paralyze creativity and innovation. One strategy for combating the ambiguity of direction and strategy is through dissent leadership or constructive disagreements (Taylor, 2017). Constructive disagreement will allow different cultural and ideological viewpoints to emerge, thereby promoting a more inclusive environment (Chin et al., 2016). 
As teams embrace diversity, the likelihood of disagreements increases. Leaders can prepare by investing in human relations skills that leverage diversity as a strength. Confrontation can be difficult, especially in the workplace. It is easy for employees to agree in order to avoid conflict rather than disagree and feel their job is in jeopardy. There are plenty of sites that offer help for employees who wish to disagree with their boss, but the onus should be on the employer to create an environment that invites constructive disagreement. This approach can sound counterproductive; however, constructive disagreement separates the person from the idea or perspective, enabling the opportunity to listen to others and fully accepting that one's mind can change with new data or information (Miller-Lane, 2006). When leaders create a safe place and build trust among teams, members disagree constructively without damaging relationships (Komori-Glatz, 2018). The ability to challenge coworkers safely might increase creativity and productivity (Landau et al., 2001).

Leaders have a responsibility to accept various points of view in order to make informed decisions and oversee the direction of organizations. Paltridge (2012) recommends that "humility in the service of ambition is the most effective and sustainable mindset for leaders who aspire to do big things in a world filled with huge unknowns".

\section{Research Question}

This paper utilizes a qualitative discourse analysis (DA) approach to examine one overarching research question (RQ).

RQ: How do organizational leaders leverage diverse viewpoints as a necessary part of the decision-making process during large scale disruptions such as COVID-19?

The RQ guided inquiry to understand the influence of values, beliefs, and assumptions about disagreement, objection, and contention during the decision-making process among senior level leaders in an interagency task force assembled to oversee the local response to the COVID-19 pandemic in one region of the United States. Focusing on the social aspect of communication among leaders was possible in this investigation via the open coding of phrases that revealed ideological associations. The following four steps summarize the methodological approach underpinning this study.

\section{Literature Review}

This succinct review of literature exploring the existing body of knowledge on dissent leadership and distributed leadership is organized into three sections that include 1) theoretical perspective, 2) vulnerability and strength, and 3) advocacy and dissent. The study aimed to illuminate the practical nature of dissent as a construct for improved decision-making.

\subsection{Theoretical Perspective}

The theory of distributed leadership posits the title alone does not make an indi- 
vidual a leader; rather, others are empowered and encouraged to take ownership and make decisions (Hallinger \& Heck, 2010). This distribution allows those with experience or interest to lead, to develop their skills, and to distribute responsibility. This type of leadership has been demonstrated to be effective in promoting a diverse mindset, highlighting different ideas and creative solutions (Marzano \& Waters, 2009). This is an ideal framework for dissent leadership because it allows individuals to take ownership and to develop skills to advocate for themselves and others.

The American Psychological Association identified four competencies for leaders as diversity in the workforce increases: leveraging personal and social identities, utilizing a global and diverse mindset, leveraging community and organizational contexts, and promoting a diversity-supportive and inclusive climate (Chin et al., 2016). This framework further supports leading by using disagreements as a way to build strengths, creativity, and innovation. Fostering an environment in which constructive disagreements are allowed to thrive also builds flexibility, that sustains diversity. As a leader, being flexible is an invaluable tool that helps create the change needed to improve organizational effectiveness (Chin et al., 2016). A possible reason that leaders may shy away from encouraging disagreements is because it requires vulnerability. Potentially, admitting that the leader does not know everything might result in strength through humility.

\subsection{Vulnerability as Strength}

For decades there have been discussions about the role of vulnerability in leadership. Bunker (1997) notes that change in the workforce requires leaders to offer credible and authentic leadership, meaning vulnerability can be a powerful leadership tool. Glanz (2007) suggests vulnerability as a possibility for educators, encouraging higher education leadership to use it to empower educators committed to instructional excellence.

While authenticity and trust have long been identified as key components of effective leadership, they are also products of vulnerability (Lopez, 2018; Pues et al., 2012). Vulnerability in leadership means being open to other ideas, recognizing limitations, and accepting uncertainty (Brecher, 2017). Dr. Brene Brown (2012) identified that the basis of social connection is vulnerability, and that when a leader exhibits this trait, people are drawn to them with deep loyalty. Such loyalty can lead to strong bonds and trust, empowering individuals to speak up when they disagree.

Couris (2020) identified a culture of connection driven by vulnerability as being essential for navigating challenges. Furthermore, Couris (2020) explains vulnerability in leadership can be perceived as being able to listen and respond rather than direct and demand. Brown (2018) concludes that leaders must create an environment that allows people the chance to be themselves, inviting innovation, connection, service, and problem-solving. 


\subsection{Advocacy and Dissent}

Consider dissent in specific fields with considerable amounts of human interaction. Public health professionals often seek to address the social determinates of health, of which education is one. The Centers for Disease Control and Prevention (CDC) lists educating and empowering people about health issues as one of the ten essential public health services (CDC, 2020). This empowerment includes teaching people how to advocate for themselves and to feel comfortable disagreeing or seeking a second opinion. Patient advocacy creates space for cultural and lived experience differences by empowering individuals to have their voice heard. An example of this advocacy and dissent leadership is the role of the community health worker (CHW; Anderson, 2013). These Community Health Workers bridge the gap between the provider and the patient by advocating for culturally appropriate interventions (Lapidos et al., 2019). They are trained to respect diversity and advocate for their patients even if it means disagreeing with a physician. This opportunity has created a pathway for innovative approaches for reaching underserved populations. As mentioned previously, advocating for new approaches is difficult.

\section{Methodology}

As a research method, discourse analysis (DA) is a mechanism for investigating both written and spoken word and the social context from which it is derived. Johnstone (2017) suggests that DA is an open-ended approach to explore stance-taking behaviors, such as dissent, within organizational practices such as meetings. Paltridge (2012) recognizes discourse in conversation as one of several approaches that also include societal discourse, pragmatics discourse, genre discourse, grammar discourse, corpus-based discourse, and critical discourse.

\section{Sample Population}

Participants in this investigation provided demographic information. The inclusion requirements relied on participation in the interagency task force responding to the COVID-19 pandemic in one region of the United States. Members of the task force included leaders with government, public health, medicine, and communication experience. The participants volunteered to participate and understood that they would have identity protected by applying pseudonyms and omission of any identifiable information.

Demographics of Participants

\begin{tabular}{cccc}
\hline Participant & Profession & Ethnicity & Gender \\
\hline Participant \#1 “Mark" & Public Health & Caucasian & Male \\
Participant \#2 "Frank" & Government & Caucasian & Male \\
Participant \#3 "James" & Government & Caucasian & Male \\
Participant \#4 "Paula" & Communication & Caucasian & Female \\
\hline
\end{tabular}




\section{Ethics and Confidentiality}

The participants in this study are protected by the development of pseudonyms and the omission of any information that might jeopardize the anonymity of any specific institution or individual. Ethical considerations and confidentiality are vital to the research process and this study followed best practices in the development of this manuscript. Participants volunteered to engage in audio recorded interviews that was saved on a password protected device and deleted following the transcription and analysis of the data.

\subsection{Discourse Analysis Steps}

- Step 1: Define the overarching RQ.

- Step 2: Examine existing literature and theory.

- Step 3: Collect and analyze the content for patterns.

- Step 4: Review the results and draw conclusions.

\subsection{Conceptual Framework}

The conceptualization of dissent leadership as an integral skill for human progress in the face of widespread disruption relies on a practical definition tied to the existing body of knowledge. The theory of distributed leadership is primarily conducted through practical approaches and not roles and responsibilities to build capacity for improvement (Bolden, 2011). In the theoretical lens of distributed leadership, this paper reconceptualizes dissent leadership as a willingness to acknowledge diversity of thought as a critical organizational strength that embraces stance-taking behaviors to foster inclusion and improve decision-making. Refer to Figure 1 to review a depiction of the conceptual framework developed based on the review of literature and merging of dissent leadership into the distrusted leadership framework to provide a practical approach to organizational leadership.

\section{Conversational Analysis}

The quotes listed in Table 1 underpin the findings derived from analysis of conversations with members of the interagency team responding to the COVID-19 pandemic in one region of the United States. In response to semi-structured questions in one-to-one interviews, participants revealed important information about the innerworkings and dynamics of the decision-making process. The direct quotes presented are from different task force members who all have significant (more than 10 years) of leadership experience in local public affairs.

\section{Findings and Conceptual Framework}

The findings from this study reveal that widespread disruptions force organizations to engage in critical decision-making that can benefit from willing acceptance of various points of view. Importantly, differing perspectives result from diversity and inclusion in the decision-making process. Figure 2 depicts a conceptual 


\section{Dissent Leadership}

Acknowledging diversity thought as a critical organizational strength that respectfully embraces stance taking behaviors to foster inclusion.

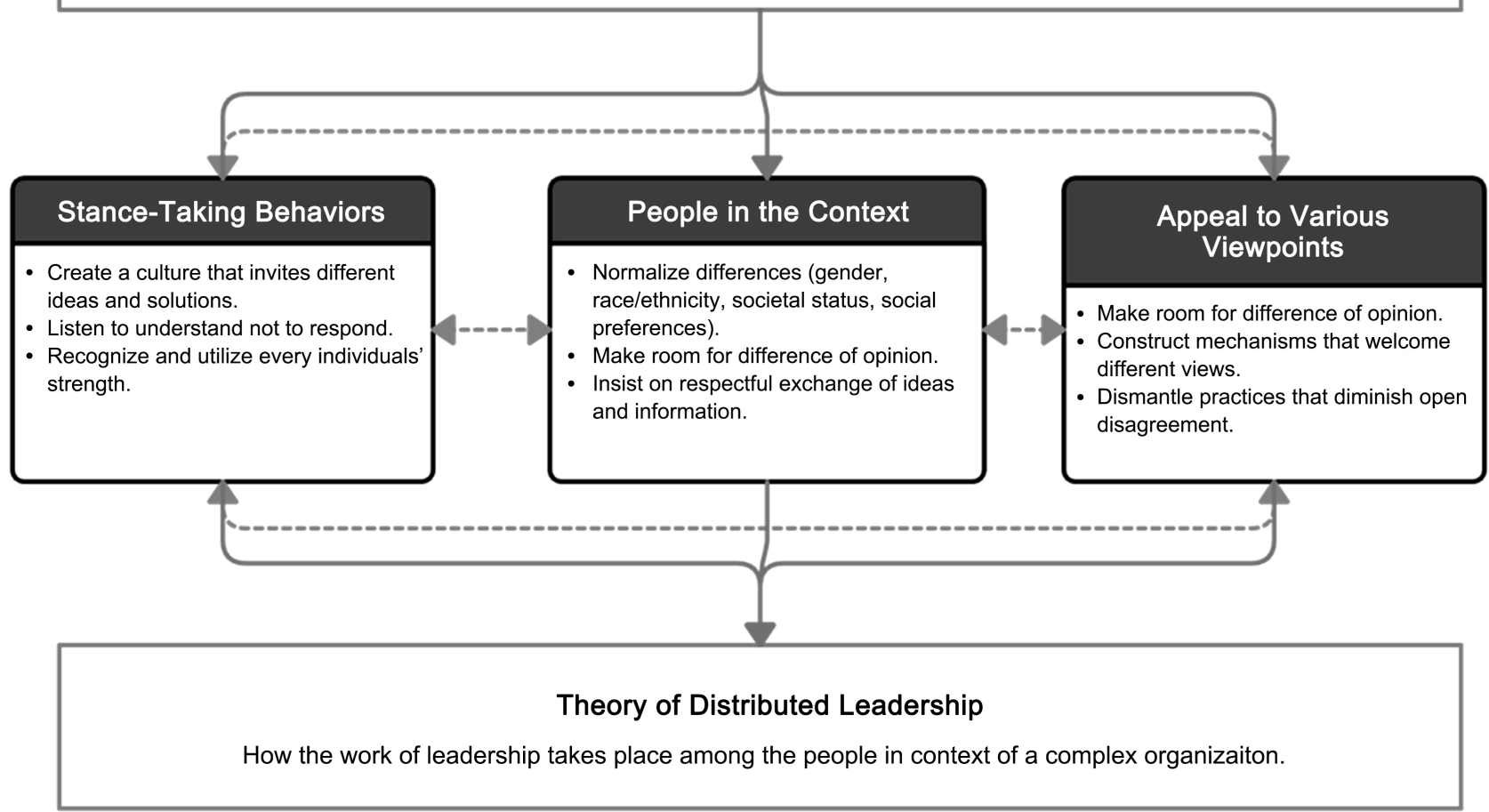

Figure 1. Theoretical convergence of dissent leadership.

Table 1. Conversational analysis.

\begin{tabular}{|c|c|}
\hline Construct & Quotes \\
\hline $\begin{array}{l}\text { Diversity in the workforce } \\
\text { increases }\end{array}$ & $\begin{array}{l}\text { Mark stated that "there were other people who were appointed from the city or county to oversee } \\
\text { these other structures, and then there were a number of other individuals invited based upon their } \\
\text { specific skills or characteristics." }\end{array}$ \\
\hline $\begin{array}{l}\text { Leveraging personal and } \\
\text { social identities }\end{array}$ & $\begin{array}{l}\text { Frank spoke about human relations explaining "not to say that there wasn't any contention, there was, } \\
\text { but that was what made this joint Emergency Operations Center I think, very successful... everybody } \\
\text { really had their eye on the ultimate goal. And that... really is the best thing that we can do for the } \\
\text { community that makes them safe, that balances the goals of preserving life, but also protecting liberty." }\end{array}$ \\
\hline $\begin{array}{l}\text { Utilizing a global and } \\
\text { diverse mindset }\end{array}$ & $\begin{array}{l}\text { James revealed "the few examples of where I can think of where things kind of went off in a bad direction, } \\
\text { or kind of indicating a head-scratcher of how did we end up working on this was often because of the lack of } \\
\text { relationship or bad relationships that we had with some of the other partners that we tried to } \\
\text { bring in." Paula confirmed the sentiment stating "Some of the conversations could be } \\
\text { enhanced by a more open mind initially but, overall it worked out". }\end{array}$ \\
\hline $\begin{array}{l}\text { Community and } \\
\text { organizational contexts }\end{array}$ & $\begin{array}{l}\text { Frank "the only contention we had initially had to do with the fact that the state was not prepared." } \\
\text { Mark concurred stating that "given the national backdrop, and sometimes the political national backdrop } \\
\text { that was going on, it was clear that different opinions were emerging about a number of things in terms } \\
\text { of the scale of the national, and maybe even state response, as well as, you know, simple measures versus, } \\
\text { or, you know, what some might refer to as restraints in versus freedoms in decision-making." }\end{array}$ \\
\hline $\begin{array}{l}\text { Promoting a diversity-supportive } \\
\text { and inclusive climate }\end{array}$ & $\begin{array}{l}\text { James said "we did not want this to be a partisan response. We did not want [it] to be viewed as a } \\
\text { one-sided ideological response. Our whole gist was how can we best protect the health of our community." }\end{array}$ \\
\hline
\end{tabular}




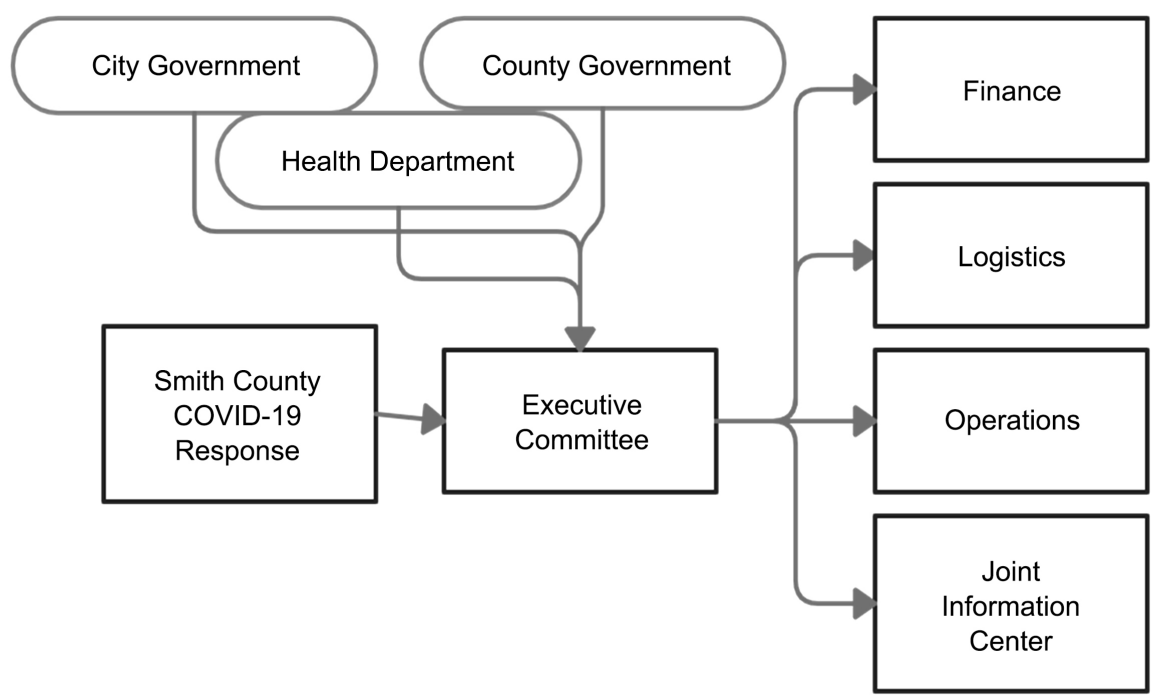

Figure 2. Conceptual framework.

framework for the interagency decision-making process. Potential benefits to organizational culture that become possible through dissent leadership include:

1) Increased productivity and creativity;

b) Improved outcomes in long-range strategic planning;

c) Advancement of human-relations skills (communication, trust, confidence).

\section{Conclusion}

Dissent leadership is a critical organizational leadership approach for equitable and inclusive decision-making. This study sought to answer the research question "How do organizational leaders leverage diverse viewpoints as a necessary part of the decision-making process during large scale disruptions such as COVID-19?". The emerging themes that answer the overarching research question confirm three potential benefits of dissent leadership including:

1) Increased productivity and creativity;

2) Improved outcomes in long range strategic planning;

3) Advancement of human-relations skills (communication, trust, confidence).

Widespread disruptions such as COVID-19 profoundly impact industries such as education and healthcare. This paper utilized conversational analysis to examine data from one-to-one interviews with leaders who served on a local interagency response team in the early stages of the COVID-19 pandemic. The findings suggest that positive outcomes result from stance-taking behaviors that manifest in the form of dissent because the decision-making process is more inclusive and diverse and considers many points of view.

\section{Conflicts of Interest}

The authors declare no conflicts of interest regarding the publication of this paper. 


\section{References}

Anderson, E. (2013). Demonstrating Advocacy and Leadership. Migrant Health Newsline, 30,7 .

Bolden, R. (2011). Distributed Leadership in Organizations: A Review of Theory and Research. International Journal of Management Reviews, 13, 251-269. https://doi.org/10.1111/j.1468-2370.2011.00306.x

Brecher, N. D. (2017). Are Leadership and Vulnerability at Odds? Journal of Property Management, 82, 23.

Brown, B. (2012). Daring Greatly: How the Courage to Be Vulnerable Transforms the Way We Live, Love, Parent, and Lead. Gotham Books.

Brown, B. (2018). Dare to Lead: Brave Work, Tough Conversations, Whole Hearts. New York: Random House.

Bunker, K. A. (1997). The Power of Vulnerability in Contemporary Leadership. Consulting Psychology Journal: Practice and Research, 49, 122-136.

https://doi.org/10.1037/1061-4087.49.2.122

Cammarota, J. (2011). The Value of a Multicultural and Critical Pedagogy: Learning Democracy through Diversity and Dissent. Multicultural Perspectives, 13, 62-69.

https://doi.org/10.1080/15210960.2011.571546

CDC Centers for Disease Control and Prevention (2020). 10 Essential Public Health Ser vices. Public Health Professionals Gateway.

https://www.cdc.gov/publichealthgateway/publichealthservices/essentialhealthservices. $\underline{\mathrm{html}}$

Chin, J. L., Desormeaux, L., \& Sawyer, K. (2016). Making Way for Paradigms of Diversity Leadership. Consulting Psychology Journal: Practice and Research, 68, 49-71.

https://doi.org/10.1037/cpb0000051

Couris, J. D. (2020). Vulnerability: The Secret to Authentic Leadership through the Pandemic. Journal of Healthcare Management/American College of Healthcare Executives, 65, 248-251. https://doi.org/10.1097/JHM-D-20-00124

Glanz, J. (2007). On Vulnerability and Transformative Leadership: An Imperative for Leaders of Supervision. International Journal of Leadership in Education, 10, 115-135. https://doi.org/10.1080/13603120601097462

Hallinger, P., \& Heck, R. H. (2010). Leadership for Learning: Does Collaborative Leadership Make a Difference in School Improvement? Educational Management Administration \& Leadership, 38, 654-678. https://doi.org/10.1177/1741143210379060

Johnstone, B. (2017). Discourse Analysis (3rd ed.). Hoboken, NJ: Wiley.

Komori-Glatz, M. (2018). "Cool My Doubt Is Erased”: Constructive Disagreement and Creating a Psychologically Safe Space in Multicultural Student Teamwork. Journal of English as a Lingua Franca, 7, 285-306. https://doi.org/10.1515/jelf-2018-0012

Landau, S., Landau, B., \& Landau, D. (2001). From Conflict to Creativity: How Resolving Workplace Disagreements Can Inspire Innovation and Productivity. Hoboken, NJ: Wiley.

Lapidos, A., Lapedis, J., \& Heisler, M. (2019). Realizing the Value of Community Health Workers-New Opportunities for Sustainable Financing. New England Journal of Medicine, 380, 1990-1992. https://doi.org/10.1056/NEJMp1815382

Lopez, S. O. (2018). Vulnerability in Leadership: The Power of the Courage to Descend (Dissertation). https://digitalcommons.spu.edu/iop_etd/16

Marzano, R. J., \& Waters, T. (2009). District Leadership That Works: Striking the Right 
Balance. Solution Tree Press.

Miller-Lane, J. (2006). Constructive Disagreement, the Body, and Education for Democracy. Social Studies, 97, 16-20. https://doi.org/10.3200/TSSS.97.1.16-20

Paltridge, B. (2012). Discourse Analysis: An Introduction (2nd ed.). London: Bloomsbury.

Pues, C., Wesche, J. S., Streicher, B., Braun, S., \& Frey, D. (2012). Authentic Leadership: An Empirical Test of Its Antecedents, Consequences, and Mediating Mechanisms. Journal of Business Ethics, 107, 331-348. https://doi.org/10.1007/s10551-011-1042-3

Taylor, B. (2017). True Leaders Believe Dissent Is an Obligation. Harvard Business Review. https://hbr.org/2017/01/true-leaders-believe-dissent-is-an-obligation 